spiration was slow, and but a small portion of lung seemed to be acting. Towards the last, the manual examinations were omitted, as the slightest tap distressed him. The faintings became more frequent, the pain more agonizing, the difficulty in swallowing greater, until death relieved him from his sufferings, on the 30th of July.

Post-mortem examination, twelve hours afterwards.-The examination was made by C. Boromar, Esq., of Leicester, and myself. The body was considerably emaciated, and decomposition already commenced. On raising the sternum, the left side of the chest was found densely filled with a hard, unyielding substance; the right lung very much collapsed. The heart was firmly pressed against the thoracic parietes, and the pericardium was adherent. On endeavouring to remove the contents of the thorax, we found the whole of the left lung was converted into a mass of cretaceous tubercular matter, firmly adherent, in the whole extent, to the costa. The right lung presented a remarkable difference, breaking up like so much moist tissue paper, and covering the hands with a black fluid, having every appearance of being a melanotic production; but a very small portion of the inferior part of this lung was capable of carrying on respiration. On opening the pericardium, the heart was found about the natural size, though rather atrophied. The valves were quite healthy; lining membrane of heart dark, as if saturated with black, putrid blood; substance of heart very soft. In the wall of the left ventricle, Mr. Boromar discovered a large scirrhous tubercle, or rather tumour, about the size of a walnut, of a cartilaginous hardness, the centre not so firm as the exterior. On further removing lumps of the strangely metamorphosed left lung, we found the first, second, third, and fourth ribs quite carious and brittle; the under surface of the left clavicle was sharp, rough, and in the same condition. We found the vertebræ diseased to a much greater extent than I should have thought likely to exist, without having caused more characteristic symptoms to exist. The first and second dorsal vertebræ were so perfectly carious, that the finger could be readily placed upon the theca of the spinal cord. None of the other viscera showed any marked disease. The brain was not examined. The csophagus, as expected, was found flattened, and partially obstructed, by the pressure of the diseased mass, fully accounting for the difficulty experienced in swallowing.

I was much puzzled, at first, with this case. Everything showed that great structural change had occurred, but of what nature could not be so easily detected. The stethoscope was of use, though negatively, assisting considerably in deciding what the disease was not. Hydrothorax, hepatization, aneurism, \&c., were all dismissed, and the case considered to be one of some rare organic alteration; and judging from concomitant symptoms, very probably malignant. The prognosis and treatment, after this decision, became readily determined. He was consequently placed as much as justifiable under the influence of opiates, morphia, and compound spirit of sulphuric ether. It is gratifying to reflect that the old veteran (he had fought at Waterloo) was not tortured by a meddlesome and experimental mode of treatment, as the result proved that all such must have been attended with disappointment. We were obliged to discontinue the examination, Mr. Boromar having an engagement elsewhere, and my attention being directed to a wound in the finger, caused by a spicula of carious bone.

Darlington, June, 1848.

\section{REMARKS ON THE OPERATIONS FOR EXCISING PARTS OF THE HIP-JOINT IN SCROFULOUS CARIES OF THE ARTICULATION.}

\section{By H. BURFORD NORMAN, F.R.C.S.,}

SURGEON TO THE ST. MARYLEBONE GENERAL DISPENSARY, TO THE
WESTERN OPHTHALMIC INSTITUTION, AND TO THE BLENHEIM-STREET WESTERN OP

ThE attention of the readers of ThE LANCET has been drawn of late, by Mr. Henry Smith, to the revival of operations for removing parts of the upper end and head of the femur in certain cases of disease of the hip-joint. There is no great difficulty in the performance of these operations to any one accustomed to surgical manipulations, nor danger of injuring important vessels or nerves; and I would not be considered as opposed to their fair trial in well-selected cases. At this moment indeed I am watching, with much interest, a case, in which I contemplate operating. But there are circumstances in the present day, and in the existing state of our profession, which make great caution needful, lest we be hurried away too rapidly after novelties or revived antiquities, and be led to act, as seeking our own interest and renown, with more zeal than for the welfare of our patients. In surgery such caution is much needed, and before we undertake any proposed operative procedures, we are bound to consider seriously all reasonable objections to them, and to weigh well such known circumstances as militate against them. If we think, further, that these circumstances are likely to be overlooked, we are bound to bring them forward.

In respect of the operations now considered, the "constitutional character" of the disease proposed to be benefited demands especial notice. In general, if not always, caries of the hip-joint is to be regarded as a local manifestation of scrofulous cachexia, excited, it may be, by local injury, but still only a symptom of a general disease. And the connexion between this lesion, as well as the other local manifestations of scrofula, and tubercular deposits in the various internal organs, is well understood. The frequent coincidence of such visceral disease with that of the hip-joint $I$ regard as the most serious objection to the proposed cperations. They have been performed, it appears, with some success of late in London; and in the high respectability and reputation of the operators, Messrs. Fergusson, French, my friend Mr. Walton, \&c., we have the best guarantee that due precaution was taken in the selection of the cases. My single object in these observations is to lead others to the same care, for all the objections which may exist to these or any other procedures may not occur to the minds of some sanguine of success and fame in being among the first to practise a novel, or rare and important operation. The diagnosis is all important and just, as it would afford but poor satisfaction to have amputated a thigh with the view of prolonging the life of a patient, who dies shortly after of an unsuspected aneurism; or to have extracted a cataract from an amaurotic eye; so would it be disappointing and not to our credit, after having excised the head of the femur, and scooped away at a carious acetabulum, to see our patient dying of phthisis, overlooked or not suspected in deciding on the operation. Now as such misfortunes have happened, to the great dismay of surgeon, patient, and friends, possibly the greatest care and discrimination may not always suffice to protect us from them; but they must not be neglected nor forgotten.

Another serious consideration is, the difficulty, nay, frequently the impossibility, of forming even a rational opinion of the extent of the disease with which we have to cope. We may find, for instance, the disease limited to a superficial portion of the head of the femur, and of the surface of the acetabulum; or we may find the latter extensively diseased, even perforated, and communicating with large pelvic and lumbar abscess, or collections of curdy, scrofulous matter, analogous to softened tubercle. Not long since, I inspected, with my friend Dr. Hare, the body of a female who had died of Bright's disease, and who had a large fibrinous deposit in the liver, and had suffered also from disease of the hip. In this case the acetabulum was almost destroyed; a large hole existed in it, communicating with an immense collection of curdy matter, which filled the iliac fossa and Iumbar region of one side; the iliacus and psoas muscle were degenerated, and completely infiltrated with the morbid product; the sacroiliac articulation was diseased also.

The following case, recently under my care, may serve to illustrate some of the remarks already made; its facts are not liable to be misinterpreted, as might be my comments. The diseased parts were recently exhibited at a meeting of the Harveian Society.

CASE.-C. R-, a slightly-formed girl, just three years of age, one of a large family, two children of which had died, under one year old, of some disease of the heart, but the others were healthy, was brought to me for advice on the 3rd of February last. She had been always delicate, but remarkably lively and active, and in intelligence precocious; not subject to any actual illnesses. She had frequently met with hard blows and falls in following a strong propensity to clamber on the tables, drawers, \&c., in her parents' room. For about two months she had complained of pain in the inside of the right $\mathrm{knee}$, increased apparently by any movement of the $\operatorname{limb}$, and manifested further by a reluctance to walking. Her temper had been restless and irritable. She lay always on the left side, and kept the right thigh semiflexed.

On examining her, I found every attempt to move the hipjoint, whether in flexion, extension, abduction, or rotation of the thigh, resisted immediately by the muscles, though I was suffered to move the leg or the thigh, and to move the opposite thigh, in any direction. She did not cry, and could not be got to speak; and as her expression was previously sulky enough, 
there was little indication of pain produced by moving the hip, except by the muscular resistance; and the same may be said of pressure and percussion. She would not make any attempt to stand on the right foot. The hip was somewhat flattened, and the fold of the buttock less marked than on the left side. Not much change otherwise perceptible in figure or size, or in the heat and colour of the skin. Her general symptoms seemed referrible to the irritation of ascarides.

From the 3rd to the 15th several small doses of compound scammony powder with calomel were administered, and brought away a great number of ascarides, and a good deal of fotid, slimy fæces. The hip was fomented regularly with decoction of poppy-heads. The symptoms of its disease were not lessened by the removal of the intestinal irritation; three leeches were now applied. The bowels were maintained in a free state of action by a tablespoonful of black draught given occasionally. On the 19th, a blister was applied. During the remainder of the month, similar treatment was followed, with the addition of a saline mixture and minute doses of tartar emetic towards the end of the month, when there was a little increased action about the hip, and febricula accompanying it. From the middle of March to the middle of April, the vascular excitement that had existed, both local and general, was kept in abeyance. Perfect rest had been maintained, a plain nutritious diet had been given, the bowels had been carefully regulated by simple aperients generally, and an occasional mercurial dose. There appeared to be an improvement of the hip, which she allowed to be moved, and extended herself-indeed, she had been sitting up a little, and even crawled on the floor, not using the diseased limb. I had had her carried into the parks; and as her general health was not amending under confinement, and she perspired much, she was sponged with tepid salt-and-water daily.

April 13th.-General feverishness and increased heat of the hip, with returning reluctance to movement of the joint, led me to direct again perfect rest; to discontinue the quinine; to re-apply a few leeches to the joint, and to prescribe a saline mixture. Her appearance was now distinctly worse than at the beginning of the treatment-she was paler and thinner. She continued in much the same state to the 25th, requiring aperient medicine to keep up the necessary excretions for the bowels.

25th.-I had not seen her for a few days; the bowels had become so constipated that ordinary doses of medicine failed to affect them; she had been repeatedly sick also, vomiting her food mixed with the ordinary secretions of the stomach. She appeared listless; her sleep was much disturbed, and she awoke always as in a fright. A slight feverishness continued. An emetic, consisting of ten grains of ipecacuanha, was given, and acted freely, but brought away little beyond the ordinary contents of the stomach. This was followed by repeated doses of the black draught mixture this and the next day, but the bowels were scarcely moved. Three leeches were again applied to the hip.

27th.-A dose of calomel and scammony, followed by an ounce black draught, procured a copious evacuation. Sickness had ceased. Febricula continued.

29th.-Countenance flushed; pulse extremely rapid; skin hot and dry. She lay still, taking little notice, and very little food or drink. Sleep disturbed, and restless, awaking with a start. Bowels confined. Calomel and scammony repeated. Saline mixture, with a drop of diluted prussic acid, every four hours.

May 2nd.--Convulsions occurred last night; the limbs, especially of the right side, were violently agitated; the features were distorted, and the eyes squinted; fever much augmented; head hot. A grain of calomel, with two grains of antimonial powder, were ordered to be given every four hours, and cold water to be applied to the head. Saline mixture continued.

3rd.--Symptoms as yesterday, with the addition of a state of stupor almost amounting to coma; bowels constipated. A purgative powder was given; three leeches were applied to the temple; the head was shaved; cold lotions were applied to the forehead, and a blister over the occiput; hot water bottles to the feet; the calomel and antimony powders to be given every other hour.

4th.-No amendment, except very temporary, - arousing from the stupor from time to time, with more profound relapses, so that medicines could not be regularly given; bowels have not acted for three days, in spite of the calomel and the purgative given yesterday. An enema, containing half a drachm of compound extract of colocynth, and half an ounce of turpentine, was administered, and procured four copious evacuations. From this time till her death the cerebral disease progressed; she was sometimes quite coma. tose; at other times she became sensible, so as to take a little jelly, the only food she had taken for several days, and even to speak. These remissions were very short. Convulsions were sometimes very severe; the eyes turned towards the nose; the hands clenched; the teeth grinding hard against each other. A general tremor of the muscles, and violent agitation of the right side of the body, continued, with slight and short intervals, up to the 6 th, when she died, at a quarter to twelve P.M. The left side appeared comparatively free from the violence of the convulsive movements; but this was in part due to the steadying effect of lying on that side. During the last two days 1 enjoyed the assistance of my friend, Dr. Hare, in consultation. He gave full trial to various cold applications to the head, evaporating lotions, the cold douche, and ice, whilst the distant circulation was aroused by sinapisms to the feet and calves of the legs. On one occasion she appeared to be fast sinking, and was aroused by the steady dropping of cold water upon her head. It was only a short amendment.

Examination of the body, nineteen hours after death, by $D$. Hare and myself.-We remarked a general emaciation; the right leg shortened about three-quarters of an inch; the pelvis slightly raised, and the hip projecting. Grating was felt in moving the joint. An incision made from above the great trochanter towards the neck of the femur gave vent to a large quantity of thick, dirty white, creamy matter. The capsular ligament was divided around the acetabulum, and the head of the femur, being turned out, was found rough, and its cartilage destroyed over the upper two-thirds of its surface. The cancellous structure of the head of the femur, under this ulcerated portion, was soft and highly vascular, and this state extended into the neck of the bone, but did not exist under that part of the head on which the cartilage remained sound. The round ligament was absorbed. The acetabulum was rough from ulceration, and so thinned, that when afterwards examined with one finger in the pelvis, and another in its cavity, it was felt to be flexible, like a bit of parchment. The head was opened. Along the margin of the great median fissure, on the left hemisphere of the brain were found two granular deposits of $1 \mathrm{ymph}$, about the size of a fourpenny-piece. Arachnoid membrane generally thickened and milky. On removing the brain, limited but dense adhesion between the membranes connected the middle left lobe to the middle fossa of the skull, a little external to the sella turcica. Two or three teaspoonfuls of clear serum were observed in the posterior fossa and spinal canal. Dark blood flowed freely from the sinuses. Adherent to the dura mater, between the right lateral sinus and foramen magnum, was what appeared to be a small portion of cerebellum, but which proved to be a small yellowish tubercle, softened in the centre. It had been probably developed in the cerebellum, which was softened, and its fibres somewhat torn around the part corresponding to its situation in the skull. Another similar tubercle, of larger size, was found in the cortical substance of the same lobe, at its posterior part, about half an inch deep from the under surface. In the left lobe a tubercle of rather larger size was found similarly situated, and a second more anteriorly. In the brain proper no sign of disease was discovered, except about a teaspoonful of serum in each lateral ventricle. It was carefully examined without finding one tubercle. The arachnoid covering the base was much more thickened and opaque than at other parts, especially about the optic commissure and nerves extending back to the pons Varolii. The third, fourth, and the optic nerves were enveloped in a mesh of lymph deposited around them. In the chest: the left pleura free from adhesions; the right, extensively and strongly adherent, especially at the posterior and inferior aspects. The lungs presented a mottled surface, from the parts, which were of natural colour and permeable, being mixed with smaller and more numerous patches, of a liver colour, and so solidified, that pressure sufficient to rupture the air-cells, and to inflate the interlobular cellular tissue, had no effect on them. Both lungs were likewise fully studded with small grey tubercles, especially in the upper lobes. Except a slight fibrinous thickening of the capsule of the liver, over the anterior surface of the right lobe, no other lesion was discovered. This part of the examination was hurried by the coming on of night, as we were obliged to make it late, and between other engagements.

In such a case as the preceding, it is quite clear that very little benefit could have been derived, had the child lived longer, from any local measures; and the question arisesCould the existence of such severe complications as were found after death have been determined during life? The 
existence of tubercles within the encephalon could not have been diagnosed, nor justly suspected, until the irritation they occasioned gave rise to symptoms of cerebral disorder. There may, however, sometimes be good grounds for fearing their presence before symptoms so severe, as in the present case, arise, and we should never forget the possibility, in interpreting our earlier symptoms. But in reference to the state of the lungs a different answer must be given. In all probability their condition could have been satisfactorily made out. One sign, indeed, was evident after death in a marked dulness on percussion, especially over the upper part of the chest: and there can be little doubt that changes in the respiratory murmur \&c. might have been detected, sufficient to have confirmed a diagnosis; and in such a state of things my feeling is, that no operation would be justifiable. The issue of the case was just what $I$ expected from the moment that cerebral symptoms became distinct; for I had little doubt that the meningitis was due to the irritation of tubercles in or upon some portion of the brain. And the prognosis in such a disease, where there is good ground for suspecting a tuberculous origin, must be always unfavourable.

London, 1848.

REPORT OF A CASE OF

\section{DISLOCATION OF THE THIGH FORWARDS, ON THE OS PUBIS.}

By G. YEATES HUNTER, Esq., M.R.C.S., \&c., Margate.

Dislocation of the os femoris, on the horizontal ramus of the os pubis, is of very rare occurrence, and has, perhaps, seldom happened to a person seventy-seven years of age, at which extended period of life fracture of the cervix femoris is the more general result of accident.

April 20th.-Thomas C-C, of Rancorn, aged seventyseven years, while repairing the chimney of a small freehold, fell, with the ladder, from the kitchen roof, and, in falling, struck his thigh against a rail; when taken up by the neighbours, his left thigh was found to be serionsly injured. My assistant, Mr. Wm. Henry Thornton, being summoned to his assistance, was, with my son, promptly in attendance. Mr. Thornton readily detected dislocation of the os femoris on the horizontal ramus of the pubes, and having failed to reduce it by fixing the pelvis, and extension with towels, sent home for Weiss's dislocation case, with which I quickly joined him. The patient was placed upon a mattrass on his sound side, and the apparatus having been properly applied, cautious and gradual extension was made in the usual manner, during which, I having lifted the head of the bone from its position on the ramus, it quickly passed into the acetabulum with a smartish snap.

I may observe that the patient is a short, compact, and, for his age, a muscular man; that the dislocation was more readily reduced than might have been expected; and that the poor man is going on well, no untoward symptoms having supervened.

Margate, May, 1848 .

\section{LOCAL AN ESTHESIA;}

NOTES ON ITS ARTIFICIAL PRODUCTION BY CHLOROFORM ETC. IN THE LOWER ANIMALS, AND IN MAN.

BF J. Y. SIMPSON, M.D., F.R.S.E.,

PROFESSOR OF MIDWIFERY IN THE UNIVERSITY OF EDINBURGH.

A FEw months ago, I published some remarks, with the object of proving that the artificial production of a state of general anæesthesia before the performance of surgical operations, was not altogether an idea of modern times.* I showed that Pliny, Apuleius, and other early writers, aver that such a state of general anæesthesia can be produced by using mandragore; and that, in the thirteenth century, Theodoric had published a receipt for producing it by the inhalation of vapours arising from the watery extracts of various narcotic herbs. In our own days, this receipt of Theodoric's has been apparently found quite sufficient for the purpose by Dauriol.

The ancients seem also to have entertained the idea of the possibility of producing a state of local and limited anæsthesia in any part to be operated upon. Dioscorides, who repeatedly mentions the production of general anæesthesia by mandragore, states it as a matter of report, that local anæesthesia in a part was capable of being produced by the application of the
Memphian stone. "The Memphian stone (says he) is found in Egypt, near Memphis, of the size of a calculus, fatty, and of different colours. They say that this, when bruised and spread over parts that are to be cut or cauterized, without danger, so obtunds their sensibility, that they do not feel pain," (Hoc tradunt trito et illito partes quæ urendæ vel secandæ sunt citra periculum ita obstupescere, ut non sentiant cruciatum.)*

Whilst we may entirely doubt that local anæsthesia was capable of being produced by such an apocryphal application as the above, the passage is curious, as evidence that the idea of obtunding a single part of the body against the pain of an operation was not unknown or unthonght of in former times. Nay, many old authorities believed that against the fire ordeal any part of the body could be so protected and defended by previous applications, that the human hand, for instance, should not feel the contact of the red-hot iron. 'The writings of Salverte and Beckmann contain ample notices on this disputed question. Upwards of half a century ago, Dr. Moore ingeniously proposed to effect a local anæesthesia of any limb that was to be operated upon by the surgeon, by previously compressing with tourniquets and pads the nervous trunks going to that limb; and he has left us one interesting account of a case of amputation at St. George's Hospital, in which this plan was tried with partial success by John Hunter.

The possible production of local anæsthesia by this or by other means, is certainly an object well worthy of study and attainment. Surgeons everywhere seem to be more and more acknowledging the facility, certainty, and safety, with which the state of general anæsthesia can be produced at will before operating, as well as the moral and professional necessity of saving their patients from all unrequisite pain. But if we could by any means induce a local anæsthesia, without that temporary absence of consciousness which is found in the state of general anæsthesia, many would regard it as a still greater improvement in this branch of practice. If a man, for instance, could have his hand so obtunded that he could see, and not feel, the performance of amputation upon his own fingers, the practice of anæsthesia in surgery would, in all likelihood, advance and progress even still more rapidly than it has done.

In the following remarks, it is my object to state the results of a number of experiments which I have performed, first, upon the lower animals, and secondly, upon man, with a view to the possibility of the production of such a state of local anæsthesia, by the application of chloroform and other anæsthetic agents to individual parts of the body.

\section{1.-Production of Local Ancesthesia in the Lover Animals.}

At a meeting of the Medico-Chirurgical Society of Edinburgh, held on the 17th March, I took occasion to state that I had successfully chloroformed several of the lower animals, as annelida, crustacea, fishes, \&c.; that in some, and more especially in the common earthworm, (lumbricus terrestris) I had been able to produce local anzsthesia by applying the chloroform vapour locally; and had thus, at will, rendered anæsthetic individual parts and portions of the worm, as the head merely, or the tail merely, or the middle part of the worm merely, the head and tail remaining unaffected. At the same time I recapitulated what I had stated at one of the February meetings of the Society, that in the human subject local anæsthesia of a portion of the gums could be produced by rubbing the part with hydrocyanic acid. After the date of the above meeting, I was led to make some additional experiments upon the possible production of local anresthesia in man; and in reporting the proceedings of the preceding sederunt of the Society in the last number of the Monthly Journal of Medical Science, the editor has stated, in a short foot-note, some of the results of these experiments upon the human subject.-(See Monthly Journal, No. xci. p. 48.)

Nothing could be more curious or satisfactory than the experiments alluded to on the production of local anesthesia by the local application of chloroform-vapour to different parts of the body of the earthworm. The resulting degree of local anzsthesia in the part exposed, is generally, in the course of two or three minutes, most complete, as regards both sensation and motion. In fact, after being sufficiently exposed, the chloroformed portion of the animal is quite flat and flaccid, does not move under any irritation, and can be doubled and twisted up upon itself like a piece of loose wetted cord If the part paralyzed by the chloroform is small, it will be dragged along by the movements of the other unaffected por-

* Monthly Journal of Medical Science for December, 1847-8, p. 4501 . 